\title{
Next-generation genome sequencing can be used to rapidly characterise sequences flanking T-DNA insertions in random insertional mutants of Leptosphaeria maculans
}

\author{
Kylie Chambers ${ }^{1}$, Rohan GT Lowe ${ }^{1,2}$, Barbara J Howlett ${ }^{1}$, Manuel Zander ${ }^{3}$, Jacqueline Batley ${ }^{3,4}$,
}

Angela P Van de Wouw ${ }^{1 *+}$ and Candace E Elliott ${ }^{1+}$

\begin{abstract}
Background: Banks of mutants with random insertions of T-DNA from Agrobacterium tumefaciens are often used in forward genetics approaches to identify phenotypes of interest. Upon identification of mutants of interest, the flanking sequences of the inserted T-DNA must be identified so that the mutated gene can be characterised. However, for many fungi, this task is not trivial as widely used PCR-based methods such as thermal asymmetric interlaced polymerase chain reaction (TAIL-PCR) are not successful.

Findings: Next-generation Illumina sequencing was used to locate T-DNA insertion sites in four mutants of Leptosphaeria maculans, a fungal plant pathogen. Sequence reads of up to $150 \mathrm{bp}$ and coverage ranging from 6 to 24 times, were sufficient for identification of insertion sites in all mutants. All T-DNA border sequences were truncated to different extents. Additionally, next-generation sequencing revealed chromosomal rearrangements associated with the insertion in one of the mutants.
\end{abstract}

Conclusions: Next-generation sequencing is a cost-effective and rapid method of identifying sites of T-DNA insertions, and associated genomic rearrangements in Leptosphaeria maculans and potentially in other fungal species.

Keywords: Next-generation sequencing, Filamentous fungi, T-DNA mutants, TAlL-PCR

\section{Findings}

Forward genetics approaches, where banks of mutants with random insertions of DNA are screened for phenotype changes, are often used to study fungi that are recalcitrant to reverse genetics approaches such as gene deletion by homologous recombination [1-6]. The inserted DNA, often T-DNA from Agrobacterium tumefaciens, usually integrates at a single site [4]. Multiple isolates with random insertions are generated and screened for the phenotype of interest. The insertion site is then identified by thermal asymmetric interlaced polymerase chain reaction (TAIL-PCR) or plasmid rescue $[1,4]$. For TAIL-PCR, sequence flanking the T-DNA insertion is amplified using a set of nested T-

\footnotetext{
*Correspondence: apvdw2@unimelb.edu.au

${ }^{\dagger}$ Equal contributors

'School of Botany, the University of Melbourne, Parkville, Victoria 3010, Australia

Full list of author information is available at the end of the article
}

DNA-specific primers paired with a short degenerate primer. TAIL-PCR has been used to obtain 74 to $100 \%$ of flanking sequences in fungi such as Fusarium oxysporum, Magnaporthe oryzae, Histoplasma capsulatum, as well as the lichen fungus Umbilicaria muehlenbergii [2,7-9]. However, the rate of success in identifying insertions in other fungi such as Trichoderma reesei, and the ascomycete plant pathogens Colletotrichum higginsianum and Leptosphaeria maculans, ranges from 30 to 66\% $[1,10,11]$. For example; only 135 out of 400 (33.7\%) flanking sequences were retrieved from the right borders in an analysis of T-DNA insertional mutants of the $L$. maculans [1]. In plasmid rescue, genomic DNA of the T-DNA-containing mutant is cut with a restriction enzyme and then circularized with T4 DNA ligase, thus releasing a fragment of the T-DNA, a selectable marker and flanking genomic sequences $[3,4]$. This method requires the use of a 
T-DNA plasmid containing a bacterial origin of replication and selectable marker and its successful use depends upon the proximity of appropriate restriction enzyme sites to the T-DNA insertion. The use of next-generation sequencing, for identifying the T-DNA insertion site, can overcome these limitations. In this paper we report the use of Illumina sequencing to identify T-DNA flanking sequences in four loss-of-pathogenicity mutants identified from a bank of L. maculans insertional mutants.

L. maculans isolate IBCN18 was transformed with plasmids pKHT or pKO21 [4,12]. Plasmid pKO21 is a modified version of pPZPtk8.10, which has a hygromycin resistance gene regulated by the $A$. nidulans trpC promoter and terminator sequences inserted into the multiple cloning site. Four insertional mutants, UM176, UM314, UM316, UM317, were identified with a loss-of-pathogenicity phenotype on cotyledons of Brassica napus, as described previously [13]. Genomic DNA $(4 \mu \mathrm{g})$ was prepared from mycelia [14], digested with restriction enzymes, electrophoresed and then probed with the hygromycin resistance gene on a Southern analysis blot (data not shown). This confirmed that UM176, UM316 and UM317 each carried a single T-DNA whereas UM314 had two independent insertions of T-DNA.

Identification of the corresponding insertion sites in the four mutants was attempted using TAIL-PCR. Six different degenerate primers were used in combination with border-specific primers to amplify either the left border (LB) or right border (RB) sequences [4,15]. No amplicons containing the corresponding T-DNA sequence were produced using any combination of TAIL-PCR primers. Plasmid rescue failed to retrieve flanking sequence from UM176, in which the T-DNA was derived from pKHT. Since both TAIL-PCR and plasmid rescue failed to identify insertion sites, Illumina next-generation sequencing was then undertaken.
Genomic DNA was extracted from mycelia, then treated with RNaseA (Invitrogen). Sequencing libraries (NexteraXT; Illumina) were prepared, pooled and run on a MiSeq desktop sequencer (Illumina) [16]. Paired-end reads (150 bp) were generated, with genome coverage for the four mutants ranging from $6.6 \times-24 \times$ (Table 1 ). Sequencing reads were filtered to remove those of low quality and/or high percentage of Ns; adapter sequences were also removed. Separate BLASTN databases were generated for the sequence reads of each of the mutants using Geneious R6.0.5 (BLAST version Blast 2.2.28+). These BLAST databases were then queried using the sequences of the region between the $\mathrm{LB}$ and $\mathrm{RB}$ of the T-DNA insert. All reads that matched the T-DNA query, with expect scores of $1 \mathrm{e}^{-10}$, were retrieved and aligned to the query sequence. Flanking sequences that extended beyond the T-DNA query sequence were then used for sequence walking by querying the BLAST database again and thus retrieving more flanking sequences. This process of sequence walking was continued until enough flanking sequence was obtained to BLAST the GenBank nr database to identify neighboring regions in the L. maculans genome. Based on previous studies, a minimum alignment length of $15 \mathrm{bp}$ unambiguously identifies read locations [17]. Thus to identify an insertion site, a read needs to contain at least $15 \mathrm{bp}$ of the T-DNA sequence, as well as at least $15 \mathrm{bp}$ of L. maculans genome sequence. Therefore for each $150 \mathrm{bp}$ read, there are 120 consecutive binding sites that meet these criteria. The genome of L. maculans is approximately $45 \mathrm{Mbp}$ [18]. If each read can bind to 120 consecutive loci in the genome then the probability of identifying a T-DNA flanking sequence is $2.6 \times \mathrm{E}^{-06}$ (120 bp/45,000,000 bp) or 1 in 345,000 reads. The predicted number of reads that should flank the T-DNA insertion site for each mutant, based on these criteria, is very similar to the actual number of reads identified

Table 1 Features of flanking regions of insertional mutants of Leptosphaeria maculans analysed by Illumina next-generation sequencing

\begin{tabular}{|c|c|c|c|c|c|c|c|}
\hline \multirow[t]{2}{*}{ Mutant } & \multirow[t]{2}{*}{$\begin{array}{l}\text { Plasmid } \\
\text { inserted }\end{array}$} & \multirow[t]{2}{*}{$\begin{array}{l}\text { Number of reads } \\
\text { (Genome coverage) }\end{array}$} & \multicolumn{2}{|c|}{$\begin{array}{l}\text { Number of reads flanking } \\
\text { each border (LB, RB) }\end{array}$} & \multirow{2}{*}{$\begin{array}{l}\text { Number of nucleotides } \\
\text { deleted from T-DNA } \\
\text { borders (LB, RB) }\end{array}$} & \multirow{2}{*}{$\begin{array}{l}\text { Number of nucleotides } \\
\text { deleted from L. maculans } \\
\text { DNA (bp) }\end{array}$} & \multirow[t]{2}{*}{$\begin{array}{l}\text { Genes adjacent to } \\
\text { T-DNA insertion site }\end{array}$} \\
\hline & & & Theoretical & Observed & & & \\
\hline UM176 & pKHT & $4361600(14.5 \times)$ & $11.6,11.6$ & 16,12 & 261,4 & 26,312 & $\begin{array}{l}\text { Between } \\
\text { Lema_G56010 and } \\
\text { Lema_G101830 }\end{array}$ \\
\hline UM314 & pKO21 & $7219200(24 \times)$ & $19.3,19.3$ & 12,11 & 43,44 & 16 & $\begin{array}{l}\text { Within } \\
\text { Lema_G051670 }\end{array}$ \\
\hline UM316 & pKO21 & $1985280(6.6 x)$ & $5.3,5.3$ & 4,0 & 87, RB deleted & $\mathrm{Nd}$ & $\begin{array}{l}\text { Between } \\
\text { Lema_G008960 and } \\
\text { Lema_G008970 }\end{array}$ \\
\hline UM317 & pKO21 & $3308800(11 \times)$ & $8.8,8.8$ & 10,3 & 342,42 & 22 & $\begin{array}{l}\text { Between } \\
\text { Lema_G001330 and } \\
\text { Lema_G001340 }\end{array}$ \\
\hline
\end{tabular}

aUM314 had two T-DNA insertion sites; however, only one was identified in this study.

${ }^{\mathrm{b}}$ Translocation between Supercontig 5 and Supercontig 17 associated with T-DNA insertion.

$N d=$ Not determined. 
(Table 1). A T-DNA insertion site was located in each of the four mutants (Table 1).

In three of the four mutants, the T-DNA was located between genes and in all mutants, the LB and/or RB sequences were partially or completely deleted, possibly explaining why TAIL-PCR failed to identify the T-DNA insertion site. In UM316, no sequences flanking the RB were identified probably due to its proximity to a region of repetitive DNA. In UM176 a large deletion $(26 \mathrm{~kb})$ appeared to be associated with a translocation between two Supercontigs (17 and 5), which in the wild-type are on different chromosomes. This rearrangement resulted in deletion of at least 12 genes.

To confirm the location of insertion sites within the genomes of mutant UM176, UM316 and UM317, primers were designed to amplify from inside the T-DNA insert out into the $L$. maculans genome. For all three mutants, PCR amplicons were successfully obtained and sequenced, confirming the location of the insertions (data not shown).

With the decreasing costs of next-generation sequencing, this method of identification of insertion sites in T-DNA mutants is a cost and time-effective solution for both fungi and for plants, where PCR-based methods have not been successful. Furthermore, next-generation sequencing allows identification of chromosomal rearrangements associated with the insertion but not specifically at the insertion site. Such rearrangements are common in both plants [19] and fungi such as the basidiomycete human pathogen, Cryptococcus neoformans and the ascomycete rice pathogen Magnaporthe oryzae [2,20]. However, when using Illumina sequencing in situations where the T-DNA has inserted into a highly repetitive region of the genome, as seen in mutant UM316, it might not be possible to identify the precise location of the T-DNA junction and to quantify the amount of fungal DNA deleted during the T-DNA insertion event. Additionally, the presence of multiple T-DNA insertions or repeats within the vector sequences, such as in the case of UM314, can confound the alignment of the border sequences. Therefore all border sequences might not be identified by Illumina sequencing. However, if there is a single T-DNA insertion, in most cases the identification of just one border is sufficient to locate the insertion site and only a small deletion at the insertion site. An advantage of Illumina sequencing, as illustrated in this study, is that as little as $20-30 \mathrm{bp}$ of flanking sequence was sufficient to identify the insertion site of the T-DNA. In contrast, in a previous study, TAIL-PCR of a set of $L$. maculans mutants resulted in 33 flanking sequences of insufficient length to identify the insertion site, and a further 49 sequences gave ambiguous BLAST matches [21].

Similarly, identification of T-DNA insertion sites in mutant lines of the plant Arabidopsis thaliana has proven problematic. For example, Ji and Braam (2010) developed restriction site extension PCR, which relies on multiple PCR steps, but this method resulted in recovery of only 21 of 37 flanking sequences [22]. Lepage et al. (2013) used Roche 454 genomic sequencing and T-DNA specific primers to identify insertion sites in 55 out of 64 mutants [23]. However, this approach relies on the binding of T-DNA specific primers, which can be problematic if the T-DNA borders are mutated during integration. Furthermore, Roche454 sequencing is relatively expensive. In the current study, Illumina reads of up to $150 \mathrm{bp}$ containing as little as $20-30$ bp of $L$. maculans sequence were sufficient for identification of insertion sites; furthermore this approach overcomes potential issues with loss of T-DNA primer binding sites, and chromosomal rearrangements can be identified. With organisms of larger genome size, the amount of sequence data must be proportionately larger to maintain the same likelihood of locating the flanking regions. With the compact size of fungal genomes and the popularity of T-DNA mutagenesis [1-6], Illumina sequencing is an ideal method for characterization of insertion sites.

\section{Competing interests}

The authors declare that they have no competing interests.

\section{Authors' contributions}

$\mathrm{KC}$ analysed the mutants. $\mathrm{RL}$ designed the bioinformatics analyses. $\mathrm{BH}$ conceived the study. MZ and JB constructed sequencing libraries and performed the next generation sequencing. AV conceived the study, participated in its design and coordination, and drafted the manuscript. CE prepared the mutant banks, carried out southern analyses, and drafted the manuscript. All authors read and approved the final manuscript.

\section{Acknowledgments}

We thank the Australian Grains Research and Development Corporation and the Australian Research Council (Project DP0985953) for funding.

\section{Author details}

${ }^{1}$ School of Botany, the University of Melbourne, Parkville, Victoria 3010, Australia. ${ }^{2}$ Department of Biochemistry, La Trobe University, Bundoora, Victoria 3086, Australia. ${ }^{3}$ School of Agriculture and Food Sciences, University of Queensland, St Lucia, Brisbane, Queensland 4072, Australia. ${ }^{4}$ School of Plant Biology, University of Western Australia, Crawley, Western Australia 6009, Australia.

Received: 27 August 2014 Accepted: 14 October 2014

Published online: 07 December 2014

\section{References}

1. Blaise F, Remy E, Meyer M, Zhou L, Narcy JP, Roux J, Balesdent MH, Rouxel T: A critical assessment of Agrobacterium tumefaciens-mediated transformation as a tool for pathogenicity gene discovery in the phytopathogenic fungus Leptosphaeria maculans. Fungal Genet Biol 2007, 44:123-138.

2. Choi J, Park J, Jeon J, Chi MH, Goh J, Yoo SY, Jung K, Kim H, Park SY, Rho HS, Kim S, Kim BR, Han SS, Kang S, Lee YH: Genome-wide analysis of T-DNA integration into the chromosomes of Magnaporthe oryzae. Mol Microbiol 2007, 66:371-382.

3. Leclerque A, Wan H, Abschutz A, Chen S, Mitina GV, Zimmermann G, Schairer HU: Agrobacterium-mediated insertional mutagenesis (AIM) of the entomopathogenic fungus Beauveria bassiana. Curr Genet 2004, 45:111-119.

4. Mullins ED, Chen X, Romaine P, Raina R, Geiser DM, Kang S: AgrobacteriumMediated Transformation of Fusarium oxysporum: An Efficient Tool for Insertional Mutagenesis and Gene Transfer. Phytopathology 2001, 91:173-180 
5. Rho HS, Kang S, Lee $\mathrm{YH}$ : Agrobacterium tumefaciens-mediated transformation of the plant pathogenic fungus, Magnaporthe grisea. Mol Cells 2001, 12:407-411.

6. Walton FJ, Idnurm A, Heitman J: Novel gene functions required for melanization of the human pathogen Cryptococcus neoformans. Mol Microbiol 2005, 57:1381-1396.

7. Michielse CB, van Wijk R, Reijnen L, Cornelissen BJC, Rep M: Insight into the molecular requirements for pathogenicity of Fusarium oxysporum $\mathrm{f}$. $\mathrm{sp}$ lycopersici through large-scale insertional mutagenesis. Genome Biol 2009, 10:R4.

8. Kemski MM, Stevens B, Rappleye CA: Spectrum of T-DNA integrations for insertional mutagenesis of Histoplasma capsulatum. Fungal Biol 2013, 117:41-51.

9. Park S-Y, Jeong M-H, Wang H-Y, Kim JA, Yu N-H, Kim S, Cheong YH, Kang S, Lee Y-H, Hur J-S: Agrobacterium tumefaciens-Mediated Transformation of the Lichen Fungus, Umbilicaria muehlenbergii. Plos One 2013, 8:e83896.

10. Zhong $\mathrm{YH}$, Wang $\mathrm{XL}$, Wang $\mathrm{TH}$, Jiang Q: Agrobacterium-mediated transformation (AMT) of Trichoderma reesei as an efficient tool for random insertional mutagenesis. Appl Microbiol Biotechnol 2007, 73:1348-1354.

11. Huser A, Takahara H, Schmalenbach W, O'Connell R: Discovery of Pathogenicity Genes in the Crucifer Anthracnose Fungus Colletotrichum higginsianum, Using Random Insertional Mutagenesis. Mol Plant Microbe Interact 2009, 22:143-156.

12. Gardiner DM, Howlett BJ: Negative selection using thymidine kinase increases the efficiency of recovery of transformants with targeted genes in the filamentous fungus Leptosphaeria maculans. Curr Genet 2004, 45:249-255.

13. Van de Wouw AP, Pettolino FA, Howlett BJ, Elliott CE: Mutations to LmIFRD affect cell wall integrity, development and pathogenicity of the ascomycete Leptosphaeria maculans. Fungal Genet Biol 2009, 46:695-706.

14. Sexton AC, Howlett BJ: Characterisation of a cyanide hydratase gene in the phytopathogenic fungus Leptosphaeria maculans. Mol Gen Genet 2000, 263:463-470.

15. McElver J, Tzafrir I, Aux G, Rogers R, Ashby C, Smith K, Thomas C, Schetter A Zhou Q, Cushman MA, Tossberg J, Nickle T, Levin JZ, Law M, Meinke D, Patton $D$ : Insertional mutagenesis of genes required for seed development in Arabidopsis thaliana. Genetics 2001, 159:1751-1763.

16. Zander M, Patel DA, Van de Wouw A, Lai K, Lorenc MT, Campbell E, Hayward A, Edwards D, Raman H, Batley J: Identifying genetic diversity of avirulence genes in Leptosphaeria maculans using whole genome sequencing. Funct Integr Genomics 2013, 13:295-308.

17. Unneberg P, Wennborg A, Larsson M: Transcript identification by analysis of short sequence tags-influence of tag length, restriction site and transcript database. Nucleic Acids Res 2003, 31:2217-2226.

18. Rouxel T, Grandaubert J, Hane JK, Hoede C, van de Wouw AP, Couloux A, Dominguez V, Anthouard V, Bally P, Bourras S, Cozijnsen AJ, Ciuffetti LM, Degrave A, Dilmaghani A, Duret L, Fudal I, Goodwin SB, Gout L, Glaser N, Linglin J, Kema GH, Lapalu N, Lawrence CB, May K, Meyer M, Ollivier B, Poulain J, Schoch CL, Simon A, Spatafora JW, et al: Effector diversification within compartments of the Leptosphaeria maculans genome affected by Repeat-Induced Point mutations. Nature Commun 2011, 2:n202.

19. Clark KA, Krysan PJ: Chromosomal translocations are a common phenomenon in Arabidopsis thaliana T-DNA insertion lines. Plant J 2010, 64:990-1001.

20. Idnurm A, Walton FJ, Floyd A, Reedy JL, Heitman J: Identification of ENA1 as a virulence gene of the human pathogenic fungus Cryptococcus neoformans through signature-tagged insertional mutagenesis. Eukaryot Cell 2009, 8:315-326.
21. Bourras S, Meyer M, Grandaubert J, Lapalu N, Fudal I, Linglin J, Ollivier B, Blaise $F$, Balesdent $\mathrm{MH}$, Rouxel T: Incidence of genome structure, DNA asymmetry, and cell physiology on T-DNA integration in chromosomes of the phytopathogenic fungus Leptosphaeria maculans. G3 (Bethesda) 2012, 2:891-904

22. Ji J, Braam J: Restriction site extension PCR: a novel method for highthroughput characterization of tagged DNA fragments and genome walking. PLoS One 2010, 5:e10577.

23. Lepage E, Zampini E, Boyle B, Brisson N: Time- and cost-efficient identification of T-DNA insertion sites through targeted genomic sequencing. PLoS One 2013, 8:e70912.

doi:10.1186/s40694-014-0010-y

Cite this article as: Chambers et al:: Next-generation genome sequencing can be used to rapidly characterise sequences flanking T-DNA insertions in random insertional mutants of Leptosphaeria maculans. Fungal Biology and Biotechnology 2014 1:10

\section{Submit your next manuscript to BioMed Central and take full advantage of:}

- Convenient online submission

- Thorough peer review

- No space constraints or color figure charges

- Immediate publication on acceptance

- Inclusion in PubMed, CAS, Scopus and Google Scholar

- Research which is freely available for redistribution 